\title{
ИДЕНТИФИКАЦИЯ ВRСА1/2-МУТАЦИЙ ПРИ РАКЕ МОЛОЧНОЙ ЖЕЛЕЗЫ С ПРИМЕНЕНИЕМ ТЕХНОЛОГИИ ВЫСОКОПРОИЗВОДИТЕЛЬНОГО СЕКВЕНИРОВАНИЯ
}

И. Ф. Стеценко ${ }^{1}$, А. Ю. Красненко ${ }^{1,2}$, У. С. Станоевич³ А. А. Мещеряков ${ }^{4}$, И. К. Воротников ${ }^{4}$ О. С. Дружиловская ${ }^{1}$,

В. А. Белова ${ }^{1}$, А. В. Чуров ${ }^{1,5} \square$

${ }^{1}$ Институт общей генетики имени Н. И. Вавилова РАН, Москва

2 ООО «Генотек», Москва

${ }^{3}$ Российский научный центр рентгенорадиологии МЗ РФ, Москва

${ }^{4}$ Национальный медицинский исследовательский центр онкологии имени Н. Н. Блохина, Москва

${ }^{5}$ Институт биологии, Карельский научный центр (ИБ КарНЦ РАН), Петрозаводск

Рак молочной железы (РМЖ) является одной из наиболее распространенных форм солидных опухолей. Анализ особенностей патогенеза РМЖ на молекулярном уровне с применением современных методов генетического анализа и на разных стадиях заболевания позволяет получить новые данные для их дальнейшего применения в клинической практике. Молекулярное профилирование с применением технологий высокопроизводительного секвенирования все чаще применяют в качестве клинического теста при подборе таргетных препаратов для лечения пациентов с высокорезистентными к терапии опухолями при РМЖ. Целью работы было провести таргетное секвенирование генов BRCA1 и BRCA2 в составе панели онкогенов. Из 66 образцов ДНК пациентов с опухолями молочной железы, мутации BRCA1/2 обнаружены у 39 пацентов. Найдено 78 уникальных генетических вариантов, из них 30 мутаций в гене BRCA1 и 48 мутаций в гене BRCA2. Идентифицировано 33 мутации, оказывающие влияние на сайты посттрансляционной модификации белков (РМТ-мутации).

Ключевые слова: BRCA1, BRCA2, рак молочной железы, NGS, ДНК-секвенирование, мутация, персонализированная медицина

Финансирование: работа выполнена при финансовой поддержке государства в лице Минобрнауки России (идентификатор соглашения RFMEFI60716Х0152),

$\bigotimes$ Для корреспонденции: Алексей Викторович Чуров ул. Пушкинская, д. 11, г. Петрозаводск, 185035; achurou@yandex.ru Статья получена: 03.12.2018 Статья принята к печати: 14.12.2018 DOI: 10.24075 /vrgmu.2018.074

\section{IDENTIFICATION OF BRCA1/2 MUTATIONS IN BREAST CANCER PATIENTS BY NEXT-GENERATION SEQUENCING}

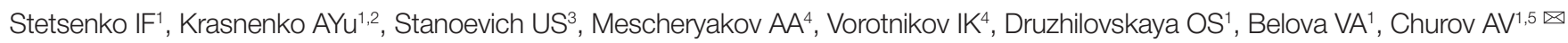 \\ ${ }^{1}$ Vavilov Institute of General Genetics of the Russian Academy of Sciences, Moscow \\ 2 Genotek Ltd., Moscow \\ ${ }^{3}$ Russian Scientific Center for X-ray Radiology of the Ministry of Health of the Russian Federation, Moscow \\ ${ }^{4}$ Blokhin Russian Cancer Research Centre, Moscow \\ ${ }^{5}$ IB KarRC RAS, Petrozavodsk
}

\begin{abstract}
Breast cancer is one of the most widespread forms of solid tumors. By analyzing the traits of breast cancer pathogenesis at the molecular level using modern genetic analysis techniques and at different stages of the disease new data can be obtained to be further utilized in clinical practice. Molecular profiling based on next-generation sequencing is being increasingly applied as a clinical test to select target drugs for treating breast cancer patients with tumors highly resistant to therapy. In this study, we performed targeted sequencing of BRCA1 and BRCA2 oncogenes. In the total of 66 DNA samples from patients with breast tumors, BRCA1/2 mutations were found in 39 patients. There were 78 unique genetic variants, including 30 mutations in $B R C A 1$ and 48 mutations in BRCA2. We identified 33 mutations affecting the sites of post-translational modification in proteins (PMT mutations).
\end{abstract}

Keywords: BRCA1, BRCA2, breast cancer, NGS, DNA-sequencing, mutation, personalized medicine

Funding: this work was supported by the Ministry of Education and Science of the Russian Federation (Project ID RFMEFI60716X0152).

$\triangle$ Correspondence should be addressed: Alexey V. Churov

Pushkinskaya 11, Petrozavodsk,185910; achurou@yandex.ru

Received: 03.12.2018 Accepted: 14.12.2018

DOI: $10.24075 / \mathrm{brsmu} .2018 .074$

Рак молочной железы (РМЖ) представляет собой одну из наиболее распространенных форм злокачественных новообразований, уступая лишь раку легкого и колоректальному раку. Заболеваемость РМЖ имеет тенденцию к росту во многих странах мира [1-4]. По этой причине ведущими задачами являются раннее выявление патологии и скрининг РМЖ.
Гены-супрессоры BRCA1 и BRCA2 играют важную роль в регуляции сигнальных путей, связанных с функционированием систем репарации ДНК. Мутации в этих генах связаны с повышенным риском развития РМЖ и некоторых других фрорм злокачественных опухолей.

Значительное количество мутаций, возникающих в опухолях, является соматическим и играет важную 
роль как в патогенезе спорадического РМЖ, так и в развитии de novo резистентности к противоопухолевым лекарственным препаратам. Спорадические формы рака выявляют в среднем в 70-80\% случаев, тогда как лишь 10\% общего числа заболевших имеют наследуемые мутации в генах BRCA1 и BRCA2 [5].

$\mathrm{Ha}$ сегодняшний день одной из актуальных задач онкогенетики являются разработка и совершенствование подходов для эффективного выбора противоопухолевых препаратов, учитывающих молекулярно-генетические особенности развития опухолей.

Целью работы было определение спектра мутаций в генах BRCA1 и BRCA2 при РМЖ с применением технологии высокопроизводительного секвенирования на платформе Illumina.

\section{ПАЦИЕНТЫ И МЕТОДЫ}

\section{Материал исследования. \\ Клиническая характеристика больных}

Для проведения исследования была собрана коллекция образцов опухолей 66 пациенток со злокачественными новообразованиями молочной железы, проходивших стационарное лечение в Национальном медицинском исследовательском центре онкологии им. Н. Н. Блохина и ФГБУ «Российский научный центр рентгенорадиологии» МЗ РФ (Москва). Средний возраст больных составил $52,5 \pm 9,7$ лет. Критерии включения в исследование: возраст от 18 до 70 лет, женский пол, наличие клинически верифицированного диагноза РМЖ. Критерии исключения: наличие других форм новообразований в анамнезе, беременность. Стадию РМЖ устанавливали согласно системе классификации TNM [6]. В исследовании принимали участие пациентки со стадиями Т1-3NO- 3MO-1.

Работу проводили с соблюдением принципов добровольности и конфиденциальности. Для проведения исследования было получено разрешение Комитета по медицинской этике при ООО «Генотек» (протокол № 5 от 17 января 2018 г.). От всех пациенток получены информированные согласия на проведение исследования. Основные клинические характеристики больных представлены в табл. 1.

\section{Выделение ДНК и контроль качества. Секвенирование панели онкогенов}

Геномную ДНК выделяли из образцов опухолевой ткани с использованием набора реагентов DNeasy Blood and Tissue Kit (Qiagen; США) согласно протоколу производителя. Измерение концентрации полученных после выделения препаратов ДНК проводили на фллуориметре Qubit 3.0 (Thermo Fisher Scientific; США). Дополнительно качество образцов ДНК оценивали с помощью электрофореза в 1\%-м агарозном геле с добавлением этидиум бромида.

Библиотеки фрагментов ДНК готовили с использованием набора реагентов NEBNext Ultra DNA Library Prep Kit for Illumina (New England Biolabs; CШA). Баркодирование библиотек осуществляли с помощью ПЦР и двух наборов реагентов: NEBNext Ultra DNA Library Prep Kit for Illumina и NEBNext Multiplex Oligos for Illumina (Dual Index Primers Set 1, New England Biolabs; США). Для контроля качества полученных ДНК-библиотек проводили измерения на приборе Agilent Bioanalyzer 2100 (Agilent Technologies; США), используя набор реагентов High Sensitivity Kit в соответствии с протоколом компаниипроизводителя.

Для обогащения кодирующих регионов генома опухоли использовали набор MYbaits Onconome $\mathrm{KL}$ v1.5 Panel (Mycroarray; США). Анализ проводили на Таблица 1. Клиническая характеристика пациенток с раком молочной железы $(n=66)$

\begin{tabular}{|c|c|}
\hline Характеристика & Значение, абс. (\%) \\
\hline Возраст (лет) & $52,5 \pm 9,7$ \\
\hline \multicolumn{2}{|l|}{ Основной диагноз } \\
\hline Рак левой молочной железы & $32(48,5)$ \\
\hline Рак правой молочной железы & $32(48,5)$ \\
\hline Двусторонний рак & $2(3)$ \\
\hline \multicolumn{2}{|l|}{ Т-стадия опухоли (согласно TNM) } \\
\hline $\mathrm{T} 1$ & $36(54,5)$ \\
\hline T2 & $29(43,9)$ \\
\hline T3 & $1(1,5)$ \\
\hline \multicolumn{2}{|l|}{ Наличие метастазов в лимфоузлах: } \\
\hline без метастазов, М0 & $56(84,8)$ \\
\hline с метастазами, M1 & $10(15,2)$ \\
\hline \multicolumn{2}{|l|}{ Экспрессия рецепторов эстрогена (ER) } \\
\hline ER+ & $53(80,3)$ \\
\hline ER- & $13(19,7)$ \\
\hline \multicolumn{2}{|l|}{ Экспрессия рецепторов прогестерона (PR) } \\
\hline $\mathrm{PR}+$ & $50(75,8)$ \\
\hline PR- & $16(24,2)$ \\
\hline \multicolumn{2}{|l|}{ Экспрессия HER2/neu (Cerb-B2) } \\
\hline Her2+ & $38(57,6)$ \\
\hline Her2- & $28(42,4)$ \\
\hline
\end{tabular}

Примечание: Значения представлены в виде (M \pm SD) или в \%; T1-T3 - стадии классификации опухоли согласно TNM; ER - экспрессия рецептора эстрогена; PR - экспрессия рецептора прогестерона; HER2/neu (Cerb-B2) - экспрессия рецептора 2-го типа эпидермального фактора роста человека. 
высокопроизводительном геномном секвенаторе HiSeq 2500 (lllumina; США) методом парных прочтений участков длиной 100 нуклеотидов. Подготовку образцов и запуск осуществляли согласно протоколам Illumina.

\section{Биоинформатическая обработка NGS-данных}

Для биоинформатической обработки полученных при секвенировании NGS-данных применяли ранее разработанный алгоритм $[7,8]$. На начальном этапе проводили оценку качества ридов, полученных при секвенировании ДНК с помощью программного обеспечения Cutadapt и картировали на референсный геном hg19 (GRCh37.p13) с помощью инструмента BWA (Burrows-Wheeler Aligner). Парные риды удаляли, используя специализированную команду rmdup в составе пакета программ SAMtools. Для обнаружения мутаций в составе массива NGS-данных применяли MuTect, при этом в качестве значимых вариантов рассматривали последовательности ДНК, число покрытий которых при секвенировании было не менее 12.

Уровень представленности мутации в образце определяли как долю (\%) ридов в точке, которые поддерживают мутацию. Функциональный эффект обнаруженных мутаций оценивали с помощью базы данных ActiveDriverDB [9]. Визуализацию мутаций, оказывающих влияние на кодируемый белок, выполняли с помощью программы ProteinPaint [10].

\section{РЕЗУЛЬТАТЫ ИССЛЕДОВАНИЯ}

Нами был проведен анализ наличия мутаций в генах BRCA1 и BRCA2 в образцах ДНК опухолей РМЖ $(n=66)$ с применением технологии высокопроизводительного

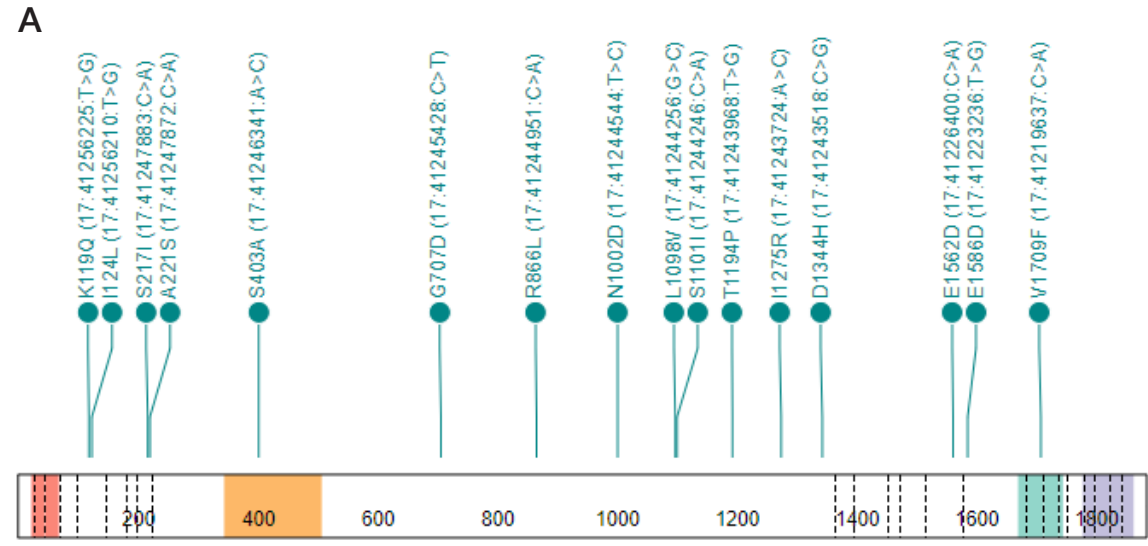

\section{BRCA 1 NM_ 007300}
RING
BRCT_assoc
BRCT
BRCT

\section{Б}

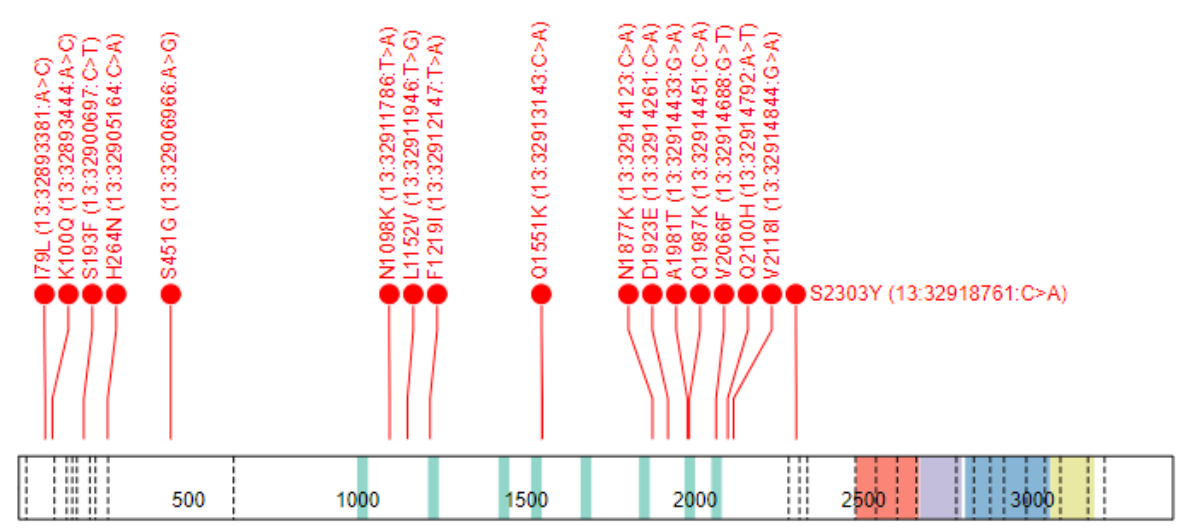

\section{BRCA 2 NM_ 000059}
BRCA2
BRCA-2_helical
BRCA-2_OB1
BRCA2DBD_OB2
BRCA-2_OB3

Рис. 1. Спектр мутаций, оказывающих влияние на сайты посттрансляционной модификации белков (РМТ-мутации), в генах BRCA1 (А) и ВRCA2 (Б), у пациентов с PMЖK $(n=39)$. * — на основе предсказания эффектов мутаций, согласно ActiveDriveDB 
Таблица 2. Мутации в генах BRCA1 и BRCA2, идентифицированные у пациентов с РМЖ

\begin{tabular}{|c|c|c|c|c|c|c|c|c|c|}
\hline Ген & $\begin{array}{c}\text { ID } \\
\text { образца }\end{array}$ & $\begin{array}{c}\text { Стадия } \\
\text { РМЖ }\end{array}$ & $\begin{array}{c}\text { Доля раковых } \\
\text { клеток в } \\
\text { образце 1, \% }\end{array}$ & $\begin{array}{c}\text { Представ- } \\
\text { ленность } \\
\text { мутации в } \\
\text { образце, \% }\end{array}$ & $\begin{array}{l}\text { Покрытие } \\
\text { в точке }\end{array}$ & $\begin{array}{c}\text { РТМ- } \\
\text { мутация }\end{array}$ & Эффект 2 & $\begin{array}{c}\text { Референсный номер } \\
2\end{array}$ & $\begin{array}{l}\text { Каноническое } \\
\text { обозначение }\end{array}$ \\
\hline \multirow{30}{*}{$B R C A 1$} & 1 & IIIA & 20 & 52 & 235 & нет & нет & Новая мутация & $17: 41246746: T>C$ \\
\hline & 2 & $\| A$ & 9 & 30 & 117 & нет & нет & rs1800744 & $17: 41226488: C>A$ \\
\hline & \multirow{4}{*}{3} & \multirow{4}{*}{ IA } & \multirow{4}{*}{70} & 4 & 106 & нет & нет & Новая мутация & $17: 41251858: T>G$ \\
\hline & & & & 3 & 115 & да & distal & Новая мутация & $17: 41223236: T>G$ \\
\hline & & & & 2 & 267 & да & proximal & Новая мутация & 17:41243968:T>G \\
\hline & & & & 1 & 439 & нет & нет & Новая мутация & $17: 41245560: C>A$ \\
\hline & \multirow{2}{*}{4} & \multirow{2}{*}{ I } & \multirow{2}{*}{30} & 4 & 116 & да & proximal & rs80357088 (dbSNP) & $17: 41247872: C>A$ \\
\hline & & & & 1 & 685 & да & proximal & rs80357192 (dbSNP) & $17: 41245428: C>T$ \\
\hline & 5 & $\| \mathrm{A}$ & 8 & 4 & 230 & да & $\begin{array}{c}\text { network-rewiring - } \\
\text { motif loss }\end{array}$ & Новая мутация & $17: 41244256: G>C$ \\
\hline & 6 & 1 & 90 & 2 & 169 & да & direct & Новая мутация & $17: 41244246: C>A$ \\
\hline & 7 & IIA & 21 & 2 & 250 & нет & нет & Новая мутация & $17: 41244207: T>C$ \\
\hline & 8 & IA & 8 & 2 & 306 & нет & нет & Новая мутация & $17: 41246576: A>C$ \\
\hline & 9 & IA & 6 & 2 & 270 & да & distal & Новая мутация & $17: 41243724: A>C$ \\
\hline & \multirow{3}{*}{10} & \multirow{3}{*}{ IA } & \multirow{3}{*}{32} & 2 & 142 & да & proximal & Новая мутация & $17: 41256210: T>G$ \\
\hline & & & & 2 & 142 & да & distal & Новая мутация & $17: 41256225: T>G$ \\
\hline & & & & 1 & 333 & да & direct & Новая мутация & $17: 41246341: A>C$ \\
\hline & \multirow{2}{*}{11} & \multirow{2}{*}{ IIB } & \multirow{2}{*}{95} & 2 & 166 & да & proximal & BRCA (TCGA MC3) & $17: 41243518: C>G$ \\
\hline & & & & 1 & 467 & нет & нет & Новая мутация & $17: 41245516: C>A$ \\
\hline & 12 & IA & 98 & 1 & 202 & да & distal & Новая мутация & $17: 41247883: C>A$ \\
\hline & 13 & IA & 15 & 1 & 660 & да & $\begin{array}{c}\text { network-rewiring - } \\
\text { motif loss }\end{array}$ & Новая мутация & $17: 41244951: C>A$ \\
\hline & 14 & IIB & 35 & 1 & 444 & нет & нет & Новая мутация & $17: 41245785: C>A$ \\
\hline & 15 & 1 & 12 & 1 & 569 & нет & нет & Новая мутация & $17: 41245228: C>T$ \\
\hline & 16 & IIB & 12 & 1 & 351 & нет & нет & Новая мутация & $17: 41245832: T>G$ \\
\hline & 17 & IIA & 57 & 1 & 413 & нет & нет & Новая мутация & $17: 41245859: C>A$ \\
\hline & 18 & IA & 12 & 1 & 211 & да & proximal & Новая мутация & $17: 41226400: C>A$ \\
\hline & 19 & $\| \mathrm{A}$ & 38 & 1 & 342 & да & distal & rs786202665 (dbSNP) & $17: 41244544: T>C$ \\
\hline & 20 & $\| \mathrm{A}$ & 32 & 1 & 307 & нет & нет & Новая мутация & $17: 41246752: C>A$ \\
\hline & \multirow{2}{*}{21} & \multirow{2}{*}{ IA } & \multirow{2}{*}{35} & 1 & 336 & да & distal & Новая мутация & $17: 41219637: C>A$ \\
\hline & & & & 1 & 379 & нет & нет & Новая мутация & 17:41246125:T >A \\
\hline & 22 & IIA & 10 & 1 & 390 & нет & нет & Новая мутация & $17: 41245026: C>A$ \\
\hline \multirow{18}{*}{$B R C A 2$} & \multirow{2}{*}{9} & \multirow{2}{*}{ IA } & \multirow{2}{*}{6} & 47 & 189 & да & distal & Новая мутация & 13:32914688:G>T \\
\hline & & & & 2 & 210 & да & distal & Новая мутация & $13: 32905164: C>A$ \\
\hline & 10 & (a) & م & 6 & 471 & нет & нет & rs28897716 (dbSNP) & 13:32911295:G>A \\
\hline & 12 & $1 A$ & 90 & 1 & 434 & да & proximal & Новая мутация & 13:32893381:A>C \\
\hline & 23 & IA & 15 & 4 & 100 & нет & нет & Новая мутация & 13:32906550:T>C \\
\hline & 24 & I & 50 & 3 & 63 & нет & нет & rs55924966 (dbSNP) & 13:32929408:G>A \\
\hline & 足 & H & 0 & 3 & 152 & нет & нет & Новая мутация & 13:32912843:G>T \\
\hline & 19 &  & 30 & 2 & 276 & нет & нет & Новая мутация & 13:32912258:C>A \\
\hline & 25 & IA & 65 & 2 & 319 & нет & нет & Новая мутация & 13:32910800:A>C \\
\hline & 14 & IIB & 35 & 2 & 316 & да & direct & rs864622305 (dbSNP) & $13: 32900697: C>T$ \\
\hline & 7 & $\| \mathrm{A}$ & 21 & 2 & 251 & нет & нет & Новая мутация & 13:32944694:G>T \\
\hline & 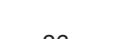 &  & 4 & 2 & 255 & нет & нет & Новая мутация & 13:32911260:A>T \\
\hline & & & & 1 & 537 & нет & нет & Новая мутация & 13:32910800:A>C \\
\hline & 7 &  & 4 & 2 & 87 & да & proximal & Новая мутация & 13:32918761:C>A \\
\hline & $2 t$ & ПI & 11 & 2 & 238 & нет & нет & Новая мутация & 13:32930703:C>A \\
\hline & & & & 2 & 130 & нет & нет & Новая мутация & 13:32931930:G>T \\
\hline & & & & 1 & 307 & да & distal & Новая мутация & $13: 32914451: C>A$ \\
\hline & 29 & I & 1 & 2 & 262 & нет & нет & Новая мутация & 13:32910800:A>C \\
\hline
\end{tabular}


Окончание таблицы 2

\begin{tabular}{|c|c|c|c|c|c|c|c|c|}
\hline \multirow{3}{*}{30} & \multirow{3}{*}{$\| \mathrm{A}$} & \multirow{3}{*}{55} & 2 & 200 & нет & нет & Новая мутация & 13:32911499:C>A \\
\hline & & & 2 & 237 & нет & нет & Новая мутация & 13:32913030:A>C \\
\hline & & & 1 & 274 & да & distal & Новая мутация & 13:32914261:C>A \\
\hline \multirow{3}{*}{10} & \multirow{3}{*}{$\mathrm{IA}$} & \multirow{3}{*}{32} & 2 & 99 & да & distal & Новая мутация & 13:32893444:A>C \\
\hline & & & 2 & 179 & нет & нет & Новая мутация & 13:32907009:T>G \\
\hline & & & 2 & 188 & да & proximal & Новая мутация & 13:32911946:T>G \\
\hline \multirow{5}{*}{4} & \multirow{5}{*}{ I } & \multirow{5}{*}{30} & 2 & 807 & нет & нет & Новая мутация & 13:32914484:C>A \\
\hline & & & 1 & 323 & нет & нет & Новая мутация & 13:32899216:G>A \\
\hline & & & 1 & 747 & нет & нет & Новая мутация & 13:32915036:A>T \\
\hline & & & 1 & 279 & нет & нет & Новая мутация & 13:32930596:T>A \\
\hline & & & 1 & 285 & нет & нет & Новая мутация & 13:32930604:A>G \\
\hline \multirow{2}{*}{21} & \multirow{2}{*}{$\mathrm{IA}$} & \multirow{2}{*}{35} & 2 & 332 & нет & нет & Новая мутация & 13:32914234:C>A \\
\hline & & & 1 & 440 & нет & нет & Новая мутация & 13:32907309:C>A \\
\hline \multirow{3}{*}{22} & \multirow{3}{*}{$\| A$} & \multirow{3}{*}{10} & 2 & 164 & нет & нет & Новая мутация & $13: 32912375: C>A$ \\
\hline & & & 1 & 298 & нет & нет & Новая мутация & 13:32907051:A>T \\
\hline & & & 1 & 358 & да & distal & Новая мутация & 13:32914844:G>A \\
\hline 2 & $\| A$ & 9 & 2 & 165 & нет & нет & Новая мутация & 13:32968849:T>C \\
\hline \multirow{2}{*}{31} & \multirow{2}{*}{ IIIC } & \multirow{2}{*}{18} & 1 & 405 & нет & нет & Новая мутация & 13:32913099:A>C \\
\hline & & & 1 & 266 & нет & нет & Новая мутация & 13:32929173:C>A \\
\hline \multirow{2}{*}{32} & \multirow{2}{*}{$\| A$} & \multirow{2}{*}{9} & 1 & 526 & да & proximal & Новая мутация & 13:32913143:C>A \\
\hline & & & 1 & 399 & нет & нет & Новая мутация & 13:32968988:C>A \\
\hline 33 & IIIA & 10 & 1 & 233 & да & distal & Новая мутация & 13:32911786:T>A \\
\hline 14 & $\mathrm{IA}$ & 15 & 1 & 362 & нет & нет & Новая мутация & 13:32936764:C>A \\
\hline 34 & $\| \mathrm{A}$ & 14 & 1 & 371 & да & distal & Новая мутация & 13:32912147:T>A \\
\hline \multirow{2}{*}{35} & \multirow{2}{*}{ IB } & \multirow{2}{*}{5} & 1 & 246 & нет & нет & Новая мутация & 13:32913558:C>T \\
\hline & & & 1 & 434 & да & distal & Новая мутация & 13:32914792:A>T \\
\hline 36 & $\mathrm{IIB}$ & 25 & 1 & 344 & да & distal & Новая мутация & 13:32914433:G>A \\
\hline \multirow{2}{*}{37} & \multirow{2}{*}{ IIB } & \multirow{2}{*}{80} & 1 & 569 & да & distal & rs374326934 (dbSNP) & 13:32914123:C>A \\
\hline & & & 1 & 275 & нет & нет & Новая мутация & 13:32937605:G>A \\
\hline 1 & IIIA & 20 & 1 & 320 & да & distal & Новая мутация & 13:32906966:A>G \\
\hline 38 & 1 & 10 & 1 & 439 & нет & нет & Новая мутация & $13: 32913444: C>A$ \\
\hline \multirow{2}{*}{39} & $\|$ & 10 & 1 & 262 & нет & нет & Новая мутация & 13:32930600:C>A \\
\hline & $\| A$ & 18 & 1 & 363 & нет & нет & Новая мутация & 13:32936793:C>A \\
\hline
\end{tabular}

Примечание: ${ }^{1}$ — по данным гистологического обследования; ${ }^{2}$ — по данным ActiveDriveDB (https://www.activedriverdb.org/).

секвенирования на платформе Illumina. В результате биоинформатической обработки полученных NGS-данных мутации в генах BRCA1 и BRCA2 найдены у 39 (59,1\%) из 66 пациентов с РМЖ. Всего в результате исследования было обнаружено 78 уникальных генетических вариантов, из них 30 мутаций в гене BRCA1 и 48 мутаций в гене BRCA2. Среди всех мутаций 70 обнаруженных вариантов идентифицированы как новые мутации (89,7\%). Список всех обнаруженных генетических вариантов представлен в табл. 2.

По результатам анализа, наиболее высокая частота отмечена для мутаций 17:41246746:T>C в гене BRCA1 (52\%) и 13:32914688:G>T в гене BRCA2 (47\%). Среди всех образцов наиболее часто встречалась мутация 13:32910800:A>C в гене BRCA2, идентисицированная в $10,7 \%$ (n=3/28) опухолей, несущих мутации BRCA2. Мутации в обоих генах BRCA1 и BRCA2 обнаружены у 11 пациентов с РМЖ (16,7\%; $n=66)$.

На основе аннотации по базам данных обнаружено 33 мутации (42,3\%), влияющие на последовательность кодируемого белка, из них 16 в гене BRCA1 и 17 в гене BRCA2. Мутации, оказывающие влияние на сайты посттрансляционной модификации белков (РМТ-мутации), представлены на рис. 1.

\section{ОБСУЖДЕНИЕ РЕЗУЛЬТАТОВ}

Персонализированная таргетная терапия находит все более широкое применение в современной онкологии. Поэтому разработка высокочувствительного и экономически эффективного подхода для доступной рутинной диагностики опухолей является одной из приоритетных задач.

В настоящее время золотым стандартом для обнаружения мутаций принято считать секвенирование методом Сенджера, однако его диагностические возможности ограничены по сравнению с более современными системами для высокопроизводительного генетического анализа. Опухолевые клетки гистологически и генетически гетерогенны, что также создает преимущества для применения технологий на основе NGS, позволяющих разрабатывать эфффективные биоинформатические алгоритмы как для детекции генетических вариантов в составе парных образцов опухолей и нормальной ткани, 
так и в составе единичных биопсий, содержащих фракцию ДНК нормальных клеток.

Мутации ключевых онкогенов BRCA1 и BRCA2 при РМЖ - одни из наиболее частых и значимых молекулярных аберраций, анализ которых представляет интерес как для оценки риска развития опухоли, клинического прогноза при РМЖ, так и для предсказания эффективности применения противоопухолевых препаратов.

Ген BRCA1 был идентифицирован в 1994 г. методом позиционного клонирования на длинном плече 17-й хромосомы. Второй ген - BRCA2 был картирован и выделен на хромосоме 13q. Гены BRCA1 и BRCA2 являются супрессорными, характеризуются аутосомно-доминантным типом наследования и высокой пенетрантностью. Молекулярные исследования BRCA1 и BRCA2, проведенные в последние годы, продемонстрировали наличие широкого спектра мутаций этих генов [5].

Международная база данных COSMIC [11] содержит свыше 900 соматических кодирующих мутаций гена BRCA1 и свыше 1400 кодирующих мутаций гена BRCA2. Значительная их часть приводит К структурным перестройкам, изменяющим функцию белковых продуктов, что снижает способность систем репарации к эфффективному восстановлению повреждений ДНК. Многие мутации BRCA1/BRCA2 относятся к миссенс-мутациям, изменяющим кодирующую последовательность и приводящим к замене одного функционального кодона на другой.

В результате проведенного нами биоинформатического анализа NGS-данных, полученных при исследовании опухолей РМЖ, было идентифицировано 78 уникальных мутаций в генах BRCA1 и BRCA2. Большая часть мутаций обнаружена в гене BRCA2. По данным литературы, гены
BRCA1 и BRCA2 значительно различаются по частоте мутаций [5].

Дальнейший анализ с применением базы данных ActiveDriveDB показал, что значительная часть генетических вариантов оказывает функциональный эффект на сайты посттрансляционной модификации кодируемых белков (см. рис. 1). Всего в ходе исследования было обнаружено 33 таких мутации, значительная доля из них ранее не аннотирована в базах данных. Для подтверждения обнаруженных в работе патогенных вариантов и статуса мутаций необходима верификация результатов исследования с применением процедуры секвенирования по Сенджеру с использованием образцов нормальной ткани.

\section{ВЫВОДЬ}

Применение высокопроизводительного таргетного секвенирования является наиболее перспективным подходом для молекулярного профилирования опухолей с целью клинического применения. Комплексный анализ мутаций с применением NGS в генах BRCA1 и BRCA2 при РМЖ позволяет идентифицировать большее число мутаций, в том числе генетических вариантов с низкой частотой мутантного аллеля, а также генетических вариантов в образцах биопсии с низким содержанием опухолевых клеток. Подходы на основе NGS, позволяющие обнаруживать мутации в составе всей кодирующей последовательности BRCA1 и BRCA2, помогут эсффективнее выявлять пациентов, которым может быть назначена адекватная терапия с применением таргетных противоопухолевых препаратов.

\section{Литература}

1. Бейсебаев Е. Н. Современные сравнительные аспекть эпидемиологии рака молочной железы. Вестник КазНМУ 2014; (1): 78-83

2. Ferlay J, Soerjomataram I, Dikshit R, Eser S, Mathers C, Rebelo M et al. Cancer incidence and mortality worldwide: sources, methods and major patterns in GLOBOCAN 2012. Int J Cancer. 2015; (136): E359-86.

3. Tao Z, Shi A, Lu C, Song T, Zhang Z, Zhao J. Breast Cancer: Epidemiology and Etiology. Cell Biochem Biophys. 2015; (72): 333-8.

4. Ghoncheh M, Pournamdar Z, Salehiniya H. Incidence and Mortality and Epidemiology of Breast Cancer in the World. Asian Pac J Cancer Prev. 2016; (17): 43-6.

5. Быкова А. В., Воротников И. К., Вишневская Я. В., Денчик Д. А. Любченко Л. Н. Роль мутации генов BRCA 1 и BRCA 2 в возникновении рака молочной железы у мужчин. Опухоли женской репродуктивной системы. 2011; (1): 29-31.

6. Giuliano AE, Connolly JL, Edge SB, Mittendorf EA, Rugo HS, Solin LJ et al. Breast Cancer-Major changes in the American Joint Committee on Cancer eighth edition cancer staging manual. CA Cancer J Clin. 2017; 67 (4): 290-303.

\section{References}

1. Bejsebaev EN. Sovremennye sravnitel'nye aspekty jepidemiologii raka molochnoj zhelezy. Vestnik KazNMU. 2014; (1): 78-83.

2. Ferlay J, Soerjomataram I, Dikshit R, Eser S, Mathers C, Rebelo M et al. Cancer incidence and mortality worldwide: sources, methods and major patterns in GLOBOCAN 2012. Int J Cancer. 2015;

7. Цуканов К. Ю., Красненко А. Ю., Коростин Д. О., Чуров А. В., Стеценко И. Ф., Плотников Н. А. и др. Рак молочной железы: анализ спектра соматических драйверных мутаций с применением высокопроизводительного секвенирования. Вестник РГМУ. 2017; (6): 52-8.

8. Цуканов К. Ю., Красненко А. Ю., Плахина Д. А., Коростин Д. О., чуров А. В., Дружиловская О. С. и др. Биоинформатический протокол для обработки NGS-данных и идентификации мутаций в солидных опухолях человека. Биомедицинская химия. 2017; 63 (5): 413-7.

9. Krassowski M, Paczkowska M, Cullion K, Huang T, Dzneladze I, Ouellette BFF et al. ActiveDriverDB: human disease mutations and genome variation in post-translational modification sites of proteins. Nucleic Acids Res. 2018; 46: D901-D910.

10. Zhou X, Edmonson MN, Wilkinson MR, Patel A, Wu G, Liu Y et al. Exploring genomic alteration in pediatric cancer using protein paint. Nat Genet. 2015; (48): 4-6.

11. Forbes SA, Beare D, Bindal N, Bamford S, Ward S, Cole CG et al. COSMIC: High-Resolution Cancer Genetics Using the Catalogue of Somatic Mutations in Cancer. Curr Protoc Hum Genet. 2016; (91): 10.11.1-10.11.37

(136): E359-86.

3. Tao Z, Shi A, Lu C, Song T, Zhang Z, Zhao J. Breast Cancer: Epidemiology and Etiology. Cell Biochem Biophys. 2015; (72): 333-8.

4. Ghoncheh M, Pournamdar Z, Salehiniya H. Incidence and 
Mortality and Epidemiology of Breast Cancer in the World. Asian Pac J Cancer Prev. 2016; (17): 43-6.

5. Bykova AV, Vorotnikov IK, Vishnevskaja JaV, Denchik DA, Ljubchenko LN. Rol' mutacii genov BRCA 1 i BRCA 2 v vozniknovenii raka molochnoj zhelezy u muzhchin. Opuholi zhenskoj reproduktivnoj sistemy. 2011; (1): 29-31.

6. Giuliano AE, Connolly JL, Edge SB, Mittendorf EA, Rugo HS, Solin LJ et al. Breast Cancer-Major changes in the American Joint Committee on Cancer eighth edition cancer staging manual. CA Cancer J Clin. 2017; 67 (4): 290-303.

7. Cukanov KJu, Krasnenko AJu, Korostin DO, Churov AV, Stecenko IF, Plotnikov NA i dr. Rak molochnoj zhelezy: analiz spektra somaticheskih drajvernyh mutacij s primeneniem vysokoproizvoditel'nogo sekvenirovanija. Vestnik RGMU. 2017; (6): 52-8
8. Cukanov KJu, Krasnenko AJu, Plahina DA, Korostin DO, Churov AV, Druzhilovskaja O. S. i dr. Bioinformaticheskij protokol dlja obrabotki NGS-dannyh i identifikacii mutacij v solidnyh opuholjah cheloveka. Biomedicinskaja himija. 2017; 63 (5): 413-7.

9. Krassowski M, Paczkowska M, Cullion K, Huang T, Dzneladze I, Ouellette BFF et al. ActiveDriverDB: human disease mutations and genome variation in post-translational modification sites of proteins. Nucleic Acids Res. 2018; 46: D901-D910.

10. Zhou X, Edmonson MN, Wilkinson MR, Patel A, Wu G, Liu Y et al. Exploring genomic alteration in pediatric cancer using protein paint. Nat Genet. 2015; (48): 4-6.

11. Forbes SA, Beare D, Bindal N, Bamford S, Ward S, Cole CG et al. COSMIC: High-Resolution Cancer Genetics Using the Catalogue of Somatic Mutations in Cancer. Curr Protoc Hum Genet. 2016; (91): 10.11.1-10.11.37. 